\title{
Regulation of Stat3 nuclear export
}

\author{
Samita Bhattacharya ${ }^{1}$ and Christian Schindler ${ }^{1,2}$ \\ ${ }^{1}$ Department of Microbiology, and \\ ${ }^{2}$ Department of Medicine, College of Physicians and Surgeons, Columbia University, New York, New York, USA
}

Stat 3 is the most pleiotropic member of the signal transducer and activator of transcription (STAT) family of transcription factors and mediates pivotal responses for the cytokine family. In resting cells, STATs, including Stat3, reside largely in the cytoplasm. Upon cytokine stimulation, they rapidly translocate to the nucleus, where they promote the expression of target genes. During the subsequent period of signal decay they are re-exported back to the cytoplasm in preparation for the next round of signaling. This process of nuclear export can be blocked by the fungal toxin leptomycin B (LMB). In contrast to what appears to be the case for Stat $1, \mathrm{LMB}$ treatment not only blocks the poststimulation export of Stat 3 from the nucleus back to the cytoplasm, but also promotes the nuclear accumulation of Stat 3 in resting cells. Remarkably, the LMB-dependent nuclear accumulation of Stat 3 in resting cells is independent of tyrosine phosphorylation, highlighting the existence of a "basal" signaling pathway. Subsequent studies identified three nuclear export signal (NES) elements. Two of these elements, Stat ${ }^{306-318}$ and Stat $3^{404-414}$, corresponded to those recently identified in Stat 1 , and a third, Stat $3^{524-535}$, is novel. Stat $3^{306-318}$ appears to be important in the rapid nuclear export seen after stimulation (poststimulation export), whereas the Stat $3^{404-414}$ and Stat $3^{524-535}$ play a more important role in regulating basal nuclear export. In summary, these studies indicate that the process of Stat 3 nuclear export is dependent on multiple NES elements.

J. Clin. Invest. 111:553-559 (2003). doi:10.1172/JCI200315372.

\section{Introduction}

STATs (signal transducers and activators of transcription) are a family of conserved transcription factors that transduce high-fidelity signals for the cytokine family of ligands and receptors (reviewed in refs. 1-3). Although STATs are most frequently recognized for their role in regulating both innate and acquired immunity, Stat 3 has also been determined to regulate development in several cell types. This uncharacteristically pleiotropic response has been attributed to the large number of cytokines for which Stat 3 transduces signals. This includes most if not all members of the IL-6, IL-10, and type I IFN family of cytokines (3, 4). Consistent with these observations, targeted deletion of the Stat 3 gene is associated with early embryonic death, and constitutive activation of Stat 3 has been associated with cancer (5-7). These observations suggest that Stat3 activity may need to be particularly tightly regulated. As is the case with other STATs, Stat 3 is predominately cytoplasmic in resting cells (8-11). This facilitates the ability of STATs to transduce signals directly

Received for publication February 27, 2002, and accepted in revised form December 9, 2002.

Address correspondence to: Christian Schindler, Columbia University, HHSC 1208, 701 West 168th Street, New York, New York 10032, USA. Phone: (212) 305-5380;

Fax: (212) 543-0063; E-mail: cws4@columbia.edu.

Conflict of interest: The authors have declared that no conflict of interest exists.

Nonstandard abbreviations used: signal transducers and activators of transcription (STAT); nuclear export signal (NES); GFP-Stat3 (G-St3); electrophoretic mobility shift assay (EMSA); leptomycin B (LMB); cycloheximide (CHX); actinomycin D (ActD); 1,4 diazabicyclo [2.2.2] octane (DABCO); nuclear localization signal (NLS). from the receptor to appropriate target genes in the nucleus (1-3). Specifically, Stat 3 is rapidly activated at cytokine receptors in a Janus kinase-dependent manner, whereupon it dimerizes and rapidly translocates to the nucleus. In the case of Stat 1 and Stat2, nuclear translocation has been shown to be dependent on a "classical" import pathway (i.e., NPI-1/importin- $\alpha 5$ and Ran/GTP) (12-17). Activated Stat3 also appears to translocate to the nucleus by an analogous NPI-1dependent pathway (S. Bhattacharya and C. Schindler, unpublished observation).

In contrast to the poorly understood process of STAT nuclear import, recent studies on Stat1 have provided insight into how Stat 1 is exported from the nucleus during the period of signal decay that follows activation. At least two NES (nuclear export signal) elements, which function in a Crm1-dependent manner, have been identified $(15,18,19)$. The current study explores the regulation of Stat 3 nuclear export and has identified three NES elements that control this process. Unexpectedly, two of these elements appear to regulate the level of Stat 3 found in the cytoplasm of resting cells, highlighting the existence of a basal nuclear export pathway. These observations are consistent with recent studies implicating a "nonclassical" Stat1-dependent signaling pathway, which appears to regulate the expression of important housekeeping genes $(15,20)$.

\section{Methods}

DNAs. Both wild-type Stat 3 and an activation mutant (i.e., Stat $3^{\mathrm{Y} 705 \mathrm{~F}}$ ) $\mathrm{cDNAs}$ were a generous gift from $\mathrm{C}$. Horvath and J. Darnell (21). Carboxy terminal GFPtagged proteins were generated by cloning these 
cDNAs into the EcoRI and ApaI restriction sites of EGFPC1 (BD Biosciences Clontech, Palo Alto, California, USA). Stat3 NES mutants were created by PCR mutagenesis (QuickChange; Stratagene, La Jolla, California, USA) with GFP-Stat3 (G-St3) serving as the templates (for detailed list of primers, see supplementary Table 1, http://www.jci.org/cgi/content/full/111/ 4/553/DC1). The Rev1.4-GFP and the Rev1.4NES-GFP were generous gifts of B.R. Henderson (22). Doublestranded oligonucleotides encoding putative NES elements (see supplementary Table 1, http://www.jci.org/ cgi/content/full/111/4/553/DC1) were cloned into the BamHI and AgeI sites of pREV1.4-GFP.

Cell culture and biochemical studies. HEK293 and HepG2 cells (American Type Culture Collection, Manassas, Virginia, USA) were grown as reported previously $(23,24)$. HEK293 cells were transfected by the calcium phosphate method after a 5- to 10 -min pretreatment with $25 \mathrm{mM}$ chloroquine (Sigma-Aldrich, St. Louis, Missouri, USA (24). Whole cell extracts were prepared $24 \mathrm{~h}$ later, either before or after IFN- $\alpha$ stimulation $(1,000 \mathrm{U} / \mathrm{ml}, 20 \mathrm{~min}$; Genentech Inc., South San Francisco, California, USA), through extraction $\left(30 \mathrm{~min}, 4^{\circ} \mathrm{C}\right)$ of $10^{7}$ cells in $100 \mu \mathrm{l}$ of buffer C (20\% glycerol, 20 mM HEPES, $\mathrm{pH} 7.9,1.5$ $\mathrm{mM} \mathrm{MgCl}_{2}, 0.2 \mathrm{mM}$ EDTA, $420 \mathrm{mM} \mathrm{NaCl}, 0.2 \mathrm{mM}$ PMSF, 1 mM DTT, $100 \mu \mathrm{M} \mathrm{Na}_{3} \mathrm{VO}_{4}$ ).

Immunoblot studies were carried out as reported previously $(23,24)$. Briefly, extracts $(2-4 \mu \mathrm{l})$ prepared from unstimulated or IFN- $\alpha$-stimulated HEK293 cells were fractionated on $10 \%$ SDS-polyacrylamide gels, transferred to nitrocellulose, sequentially immunoblotted with anti-phosphotyrosine-Stat3 (New England Biolabs Inc., Beverly, Massachusetts, USA) or anti-Stat3-specific Ab's (C-20; Santa Cruz Biotechnology Inc., Santa Cruz, California, USA) and then visualized with ECL (Amersham). Electrophoretic mobility shift assays (EMSAs) were performed with an IRF-1 GAS probe (gatcGATTTCCCCGAAAT) (Oligos Etc. Inc., Wilsonville, Oregon, USA) as described previously $(25,26)$.

Immunofluorescence assays. Cells were seeded onto duplicated sterile coverslips in a 6-well tissue-culture plate at $20-30 \%$ confluence. The next day, they were transfected with $2.5 \mu \mathrm{g}$ DNA precipitate. Twentyfour hours after transfection, cells were studied under multiple conditions (see figure legends). Leptomycin B (LMB) was a generous gift of M. Yoshida (Department of Biotechnology, University of Tokyo, Tokyo, Japan); (27). For Rev-GFP reporter assays, samples were treated with cycloheximide (CHX; Sigma-Aldrich), actinomycin D (ActD; SigmaAldrich), and LMB, as indicated (22).

Immunofluorescence was performed as reported previously (23). Briefly, cells were fixed in $3.7 \%$ formaldehyde for $20 \mathrm{~min}$ at $22^{\circ} \mathrm{C}$, permeabilized in $0.2 \%$ Triton X-100 in PBS $(137 \mathrm{mM} \mathrm{NaCl}, 2.7$ $\mathrm{mM} \mathrm{KCl}, 5.4 \mathrm{mM} \mathrm{Na} \mathrm{HPO}_{4}$, and $1.76 \mathrm{mM}$ of $\mathrm{KH}_{2} \mathrm{PO}_{4}, \mathrm{pH} 7.4 ; 2-4 \mathrm{~min}$ ), washed in $0.05 \%$ Tween 20 plus TBS (137 mM NaCl/25 mM Tris. $\mathrm{HCl}, \mathrm{pH} 7.4)$, and blocked in 3\% BSA in $0.05 \%$ Tween 20 plus Trisbuffered saline (30 $\mathrm{min})$. Samples were stained with anti-Stat3 (1:250 dilution of C-20; Santa Cruz Biotechnology Inc.) followed by a Cy3-conjugated secondary Ab (1:500; Jackson ImmunoResearch Laboratories Inc., West Grove, Pennsylvania, USA). After washing with TBS $(5 \times 5 \mathrm{~min})$, coverslips were mounted in $2 \% \mathrm{wt} / \mathrm{vol} 1,4$ diazabicyclo [2.2.2] octane (DABCO; Sigma-Aldrich); 15\% Tris, pH 8.6, 0.5 M, and $85 \%$ glycerol. The slides were examined under a Nikon Eclipse TE300 microscope after excitation at $550 \mathrm{~nm}$ (Cy3). Cells expressing GFP-fusion proteins were also fixed with $3.7 \%$ formaldehyde, but then viewed directly after excitation at $495 \mathrm{~nm}$ on the Nikon Eclipse TE300 and $488 \mathrm{~nm}$ on a Zeiss confocal microscope running LSM 410 software.

\section{Results}

LMB induces nuclear accumulation of endogenous Stat3. To explore the regulation of Stat3 (St3) nuclear export, two distinct cell types and signaling pathways were examined: IL- 6 stimulation in HepG2 cells and IFN- $\alpha$ stimulation in HEK293 cells (see Figure 1). As reported previously, Stat 3 was found to reside both in the cytoplasmic and nuclear compartment of resting HepG2 and HEK293 cells and then upon stimulation rapidly accumulated in the nucleus $(9,23)$. Several hours later, nuclear Stat 3 was exported back to the cytoplasm, restoring the cell back to its initial resting state (Figure 1c). Of note, changes in nuclear and cytoplasmic distribution were more robust in the HepG2 cells. Similar observations were made for Stat 1 , which is also activated by these two ligands (see supplementary Figure 1, http://www.jci.org/cgi/content/full/111/4/553/DC1).

Recent studies have determined that the re-export of Stat 1 from the nucleus back to the cytoplasm, during the poststimulation period, is dependent on Crm1, a LMB-sensitive export protein $(18,19,22,27)$. To determine whether LMB might have a similar effect on Stat3 nuclear export, it was added to HepG2 cells or HEK293 cell cultures before and after stimulation. As shown previously for Stat1, Stat3 nuclear export was effectively blocked in poststimulated cells, implicating Crm1 in this process (Figure 1e). Unexpectedly, however, Stat3 also accumulated in the nucleus of unstimulated LMBtreated cells (Figure 1d). This response was not affected by CHX treatment or serum starvation (data not shown). Moreover, the distribution of Stat 1 was not affected by LMB in resting HepG2 and 293 cells (see supplementary Figure 1, http://www.jci.org/cgi/content/full/111/4/553/DC1). These observations indicated that in addition to being exported from the nucleus after stimulation, Stat 3 is also continually exported from the nucleus of resting cells, a process that must be opposed by a process of basal nuclear import.

To determine whether the continuous nuclear accumulation of Stat 3 in resting cells was dependent on a low level of Stat 3 tyrosine phosphorylation, as had 
been suggested previously to account for the varying levels of nuclear Stat 3 in resting cells (9), Stat 3 was GFP tagged. Both wild-type Stat3 (G-St3) and Y705F mutant defective in activation (28) (G-St $\left.3^{\mathrm{Y} 705 \mathrm{~F}}\right)$ were selected for these studies. Upon expression in HEK293 cells, G-St 3 resided almost exclusively in the cytoplasm of unstimulated cells (Figure 1f). A similar low level of nuclear accumulation in unstimulated cells has been reported for GFP-tagged Stat 1 and is likely to represent a less robust basal nuclear import of the tagged proteins $(18,19)$.

As anticipated, G-St3 rapidly accumulated in the nucleus after IFN- $\alpha$ stimulation and LMB both blocked the export of G-St3 from the nucleus in poststimulated cells (Figure 1i). Likewise, LMB enhanced nuclear accumulation of G-St3 in unstimulated cells (Figure $1 \mathrm{~h}$ ). In contrast, G-St $3^{\mathrm{Y} 705 \mathrm{~F}}$ failed to translocate to the nucleus with stimulation, as anticipated. Intriguingly, however, G-St $3^{\mathrm{Y} 705 \mathrm{~F}}$ accumulated in the nucleus of LMB-treated resting cells, indicating that basal nuclear import is independent of activation (Figure 1h). Several lines of evidence argue against the possibility that G-St $3^{\mathrm{Y} 705 \mathrm{~F}}$ accumulated in the nucleus through a fortuitous association with endogenous and basally activated Stat 1 or Stat3. First, G-St3 ${ }^{\mathrm{Y} 705 \mathrm{~F}}$ did not translocate to the nucleus in stimulated cells when endogenous Stat 1 and Stat 3 are maximally activated. Second, the level of G-St $3{ }^{\text {Y705F }}$ expression substantially exceeded that of endogenous Stat3, effectively minimizing the potential of dimerizing with endogenous Stat3 (see supplementary Figure 2, http://www.jci.org/cgi/content/ full/111/4/553/DC1). Third, DNA-binding studies and coimmunoprecipitation studies failed to provide evidence for the formation of significant quantities of Stat3-G-St3 ${ }^{\mathrm{Y} 705 \mathrm{~F}}$ dimers (supplementary Figure 2,
http://www.jci.org/cgi/content/full/111/4/553/DC1). These observations demonstrate the nuclear accumulation of significant levels of Stat3 in the absence of tyrosine phosphorylation and are consistent with recent studies suggesting the nuclear accumulation of unphosphorylated Stat 1 in unstimulated HeLa cells (15). These observations imply that Crm1-dependent nuclear export is important both for restoring the cellular distribution of Stat 3 after ligand stimulation and in maintaining steady-state levels in resting cells. Thus, differences in the balance between basal nuclear import and export could readily account for differences in the cytoplasmic versus nuclear distribution of Stat 3 in resting cells.

Identification of Stat 3 NES elements. Crm 1 effects nuclear export through the recognition of a NES, which consists of short stretches of hydrophobic amino acids (predominately leucines), and fits the consensus of $\mathbf{L} \times{ }_{1-3} \mathbf{L} \times 2-3$ $\mathbf{L} \times \mathbf{L}(22,29)$. A search for Stat 3 NES consensus elements led to the identification of potential elements at residues 306-318, 404-415, and 524-533 (see Table 1). The first two of these elements have been reported recently to promote the nuclear export of Stat 1 in poststimulated cells $(15,18,19)$. To compare the potential of each of these three elements, as well as another proposed nonconsensus NES element near residue 200 (30), to mediate nuclear export, a recently developed Rev reporter system was exploited (22). This reporter, which is based on a GFP-tagged HIV Rev protein, includes a relatively weak nuclear localization signal (NLS) and a strong LMB-sensitive NES element (22). In the Rev1.4 reporter, the endogenous NES has been substituted with a unique endonuclease restriction site, allowing the introduction of test NES elements. The subcellular localization of the final construct is then dependent on a balance between the weak ActD-sensitive NLS and the test

\section{Figure 1}

Stat3 subcellular localization. (a-e) Subcellular localization of endogenous Stat3. HepG2 and HEK293 cells were studied under five different conditions: (a) unstimulated (un); (b) stimulated (st) acutely with IFN- $\alpha(20 \mathrm{~min}, 1,000 \mathrm{U} / \mathrm{ml})$ or IL-6 (20 min, $10 \mathrm{ng} / \mathrm{ml}$ ) for HEK293 and HepG2 cells respectively; (c) stimulated acutely for $20 \mathrm{~min}$ and then switched to fresh media for $4.5 \mathrm{~h}$; (d) treated with LMB $(\sim 7$ h, 5-10 ng/ml); and (e) pretreated with LMB (2 h, 5-10 $\mathrm{ng} / \mathrm{ml}$ ), stimulated acutely for $20 \mathrm{~min}$, and then switched to fresh media containing LMB for $4.5 \mathrm{~h}$. Stat 3 was visualized after fixation with a Stat3-specific Ab (C20) and a TRITC-labeled secondary Ab, after excitation at $550 \mathrm{~nm}$ (Cy3). These images were examined with a $\times 60$ objective and are representative of the more than 100 cells. (f-i) Subcellular localization of GFP-St3 and GFP-St $3^{\text {Y705F. GFP }}$ expression was evaluated $24 \mathrm{~h}$ after transfection into HEK293 cells after: (f) no treatment; (g) stimulation with IFN- $\alpha$ (20 min, 1,000 U/ml); (h) LMB (2 h, 5-10 ng/ml); and (i) LMB (2 h, 5-10 ng/ml), stimulated acutely with IFN- $\alpha(20 \mathrm{~min}, 1,000 \mathrm{U} / \mathrm{ml})$ and then switched to fresh media containing LMB $(5-10 \mathrm{ng} / \mathrm{ml})$ for $4.5 \mathrm{~h}$. GFP fluorescence was evaluated in fixed cells with a $\times 60$ objective lens. These images are representative of the more than 100 cells.

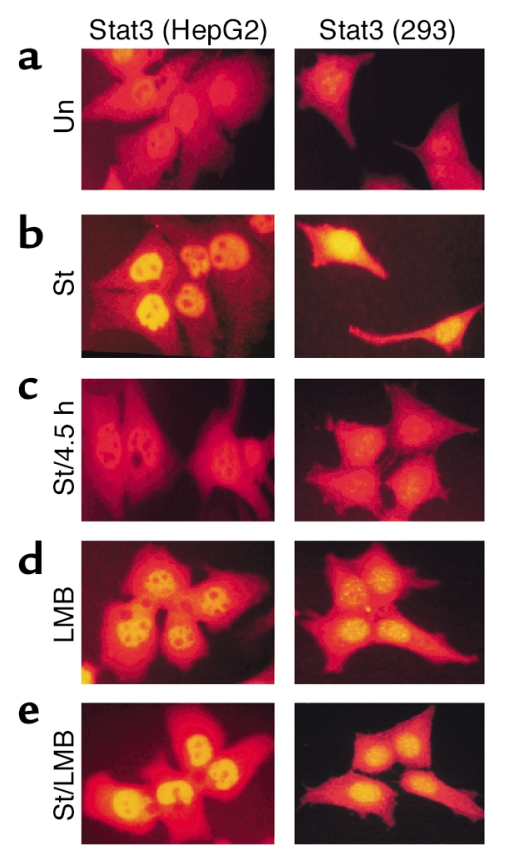

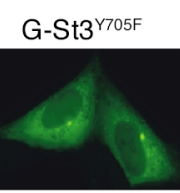

g
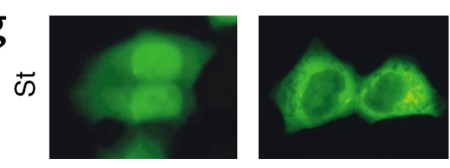

h
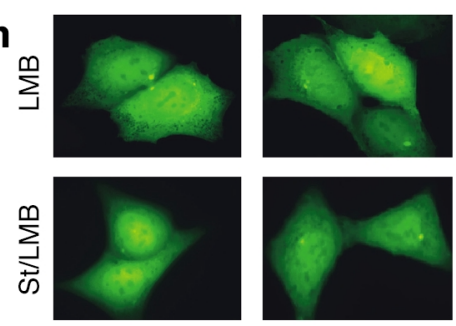
Table 1

STAT NES elements

$\begin{array}{ll}\text { NES consensus } & \text { LX }_{(1-3)} L_{(2-3)} L \mathbf{L L} \\ & \text { A A } \\ \text { mStat3524-533 } & \text { QLTTTLAEKLL } \\ \text { hStat1 } & \text { QLNMLGEKLL } \\ \text { hStat2 } & \text { QLSMLRNKLF } \\ \text { hStat4 } & \text { QLHMLAEKLT } \\ \text { hStat5a } & \text { NLVFLAQKLF } \\ \text { hStat6 } & \text { HFLFLAQKIF }\end{array}$

$\begin{array}{ll}\text { hStat } 1^{197-206} & \text { LLLKKMYLML } \\ \text { mStat } 3^{201-210} & \text { QQLEQMLTAL }\end{array}$

A A

hStat $1^{302-314}$

mStat3 $306-318$

hStat $1^{399-410}$

mStat3 $3^{404-415}$

The conservation of the NES element found at Stat 3 residues 524-533 among other STAT family members is shown under the NES consensus element ( $\mathrm{X}$ is any amino acid). Conserved leucines are shown in bold. Other large hydrophobic residues, like isoleucine, methionine or phenylalanine, which can substitute for leucine are shown in italic. The two alanine substitution mutations, introduced to cripple this NES elements at Stat 3 residues 306-318 and 404-415 (i.e., G-St $3^{404 M}$ and G-St3 $3^{306 M}$ ) are shown above the Stat3 NES elements. These mutations are analogous to those recently shown to cripple the corresponding Stat1 elements $(18,19)$.

NES element. Previous studies have highlighted the effectiveness of this reporter on number of bona fide NES elements, albeit with varying potency (22). As anticipated, the parent Rev-GFP fusion (Rev 1.4) localized to the nucleus under three test conditions: $\mathrm{CHX}$ (this eliminates the potential confusion caused by continuous protein synthesis), CHX plus ActD treatment, and CHX plus LMB treatment. Introduction of the potent NES from Rev drove the protein into the cytoplasm, but this was LMB sensitive (Rev NES; Figure 2) (22).

Next, the relative potency of each of the four candidate Stat3 NES elements (Stat3 ${ }^{201-210}$, Stat3306-318, Stat $3^{404-414}$, and Stat $3^{524-537}$ ) was evaluated (Figure 2). The Stat $3^{306-318}$ NES effectively drove the reporter into the cytoplasm, both in the presence and absence of ActD, indicating a relatively potent NES element. As anticipated, this response was also LMB sensitive. The Stat $3^{524-537}$ NES was partially excluded in the absence of ActD and significantly excluded from the nucleus in the presence of ActD, indicating a less potent NES. Again this response was LMB sensitive. The Stat $3^{404-414}$ NES was less potent, only exhibiting obvious cytoplasmic accumulation in the presence of ActD. Although not readily apparent in Figure 2, analysis of many additional cells suggested that this response was sensitive to LMB, as well. Finally, the putative Stat $3^{201-210}$ element, which had curiously been reported to exhibit activity only in Jak1-deficient cells (30), failed to exhibit any export activity. Similar results were obtained when the potency of these Rev1.4 constructs were evaluated in HepG2 cells (data not shown).

Mutational analysis of Stat 3 NES elements. The modest nuclear export activity of Stat $3^{404-414}$ in the Rev1.4 assay contradicted published observations on this element in Stat 1 (18). To determine whether this or the other Stat3 NES elements might function differently in the parent molecule, mutations of the three most effective NES elements were introduced into full-length GFP-tagged Stat3 (i.e., G-St3). In each case, this entailed substituting two conserved leucines, a strategy known to cripple NES function (see Table 1) $(18,19,22)$. Of note, mutations to the Stat $3^{306-318}$ and Stat $3^{404-414}$ elements were analogous to those reported previously for Stat1 $(18,19)$. Upon introduction into HEK293 cells, each of three mutant proteins expressed at levels comparable to wild-type G-St3 (see Figure 3a). Likewise, in response to stimulation with IFN- $\alpha$, each mutant was activated, and bound DNA, albeit G-St3 ${ }^{404 \mathrm{M}}$, did so less robustly (Figure 3, a and b).

When these GFP fusion proteins were evaluated for their cellular distribution under a number of experimental conditions, each mutant exhibited a phenotype that was distinct from wild-type G-St3 (see Figure 4). For example, G-St $3^{306 \mathrm{M}}$ exhibited a predominately cytoplasmic pattern of distribution in unstimulated cells and accumulated in the nucleus in response to IFN- $\alpha$. Nuclear export, however, was notably defective in poststimulated cells (bottom panel). This defect was not due to changes in the kinetics of phosphorylation, because G-St3 and G-St $3{ }^{306 \mathrm{M}}$ were dephosphorylated at the same rate in poststimulated cells (see supplementary Figure 3, http://www.jci.org/cgi/content/full/111/4/553/DC1). Of note, the same mutant St3 $3^{306-318}$ element failed to support nuclear export in the Rev1.4 reporter (data not shown). In contrast, G-St $3^{404 \mathrm{M}}$ and G-St $3^{524 \mathrm{M}}$ were present in both the cytoplasmic and nuclear compartments of unstimulated cells, suggesting a defect in basal nuclear export. Both of these mutants appeared to accumulate modestly in the nucleus in response to stimulation (G-St3 ${ }^{524 M}>$ G-St3 $\left.{ }^{404 M}\right)$ and then return to their prestimulation state several hours later. Of note, all three mutants appeared to exhibit at least some nuclear accumulation in LMB-treated resting cells, further supporting the notion that multiple Crm-1-dependent NES elements are active in unstimulated cells. Similar results were obtained when the mutants were expressed in COS-7 cells (data not shown). These data suggests that the NES elements Stat $3^{404-414}$ and Stat $3^{524-535}$ play a more important role in resting cells (i.e., basal export), whereas Stat $3^{306-318}$ NES plays a more important role during poststimulation export.

\section{Discussion}

The ability of STATs to rapidly transduce signals from the receptor to their targets in the nucleus is dependent on careful regulation of their subcellular distribution (reviewed in ref. 3). In unstimulated cells it is important 

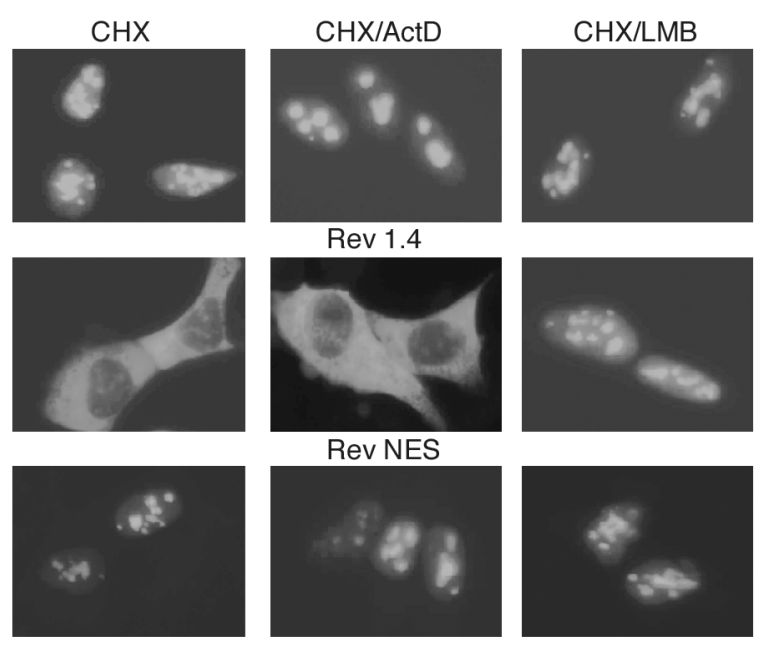

Stat3 $201-210$
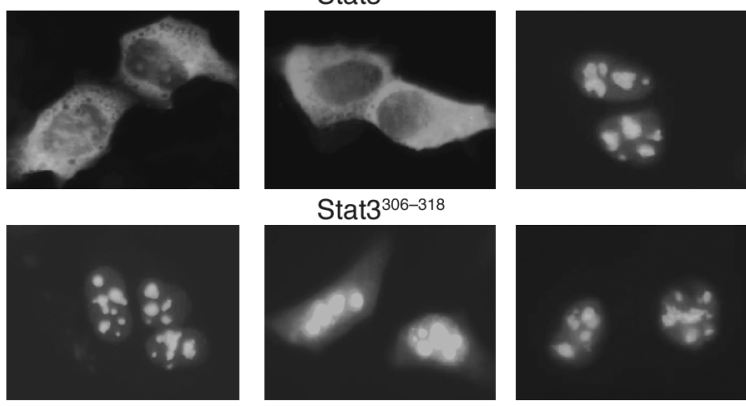

Stat3 $3^{404-414}$
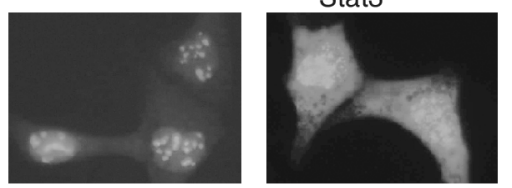

Stat3 $324-537$
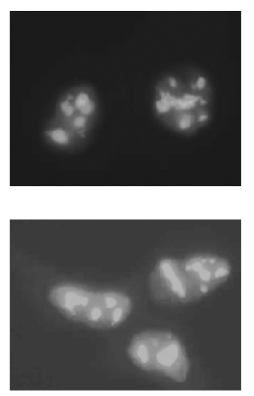

that STATs reside predominately in the cytoplasm, where they are activated. Upon stimulation they must then quickly translocate to the nucleus, where they mediate the induction of immediate early genes. To ensure that the signal transmitted by the STATs is transient, a number of counterregulatory pathways are activated. This includes the re-export of STATs back to the cytoplasm, which also appears to be linked to dephosphorylation $(18,24,31,32)$. This export also serves to prepare the cell for its next round of signaling.

The confusing observation that in some cell types Stat3 (and Stat1) are found in the nucleus of resting cells prompted a careful analysis of Stat 3 nuclear export. These studies took advantage of a unique fungal toxin, LMB, which blocks Crm-1-dependent

\section{Figure 3}

Expression and activity of wild-type and mutant GFP-Stat3. Wildtype and mutant G-St3 were transiently expressed in HEK293 cells for $24 \mathrm{~h}$ and then stimulated with IFN- $\alpha(20 \mathrm{~min}, 1,000 \mathrm{U} / \mathrm{ml})$, as indicated. Mutants included G-St3 $3^{524 M}, \mathrm{G}-\mathrm{St} 3^{404 \mathrm{M}}$, and G-St3 $3^{306 \mathrm{M}}$ (see Table 1). Whole cell extracts were prepared and either fractionated by SDS-PAGE for immunoblotting (a) or evaluated by EMSA (b). The positions of endogenous Stat3 (Endo. St3) and GFP-Stat3 (G-St3) are indicated in $\mathbf{a}$.

\section{Figure 2}

Rev1.4 reporter assays to evaluate Stat3 NES elements. Subcellular distribution of Rev1.4 constructs with no NES (Rev1.4), the native Rev NES, or putative NES elements identified at Stat 3 residues 201-210, 306-318, 404-414, and 524-537 (see Table 1). Fusion proteins were transiently expressed in 293 cells. After $24 \mathrm{~h}$, cells were treated with cycloheximide (CHX; $2 \mathrm{~h}, 5 \mu \mathrm{g} / \mathrm{ml})$, CHX plus ActD (2 $\mathrm{h}, 5 \mu \mathrm{g} / \mathrm{ml})$, or CHX plus LMB ( $2 \mathrm{~h}, 5 \mathrm{ng} / \mathrm{ml})$, fixed. GFP fluorescence was evaluated with a $\times 60$ objective lens. These images are representative of more than 100 cells.

nuclear export (27). As anticipated, LMB treatment effectively blocked Stat 3 nuclear export in postreceptor-stimulated cells. Unexpectedly, however, LMB treatment also led to nuclear accumulation of Stat 3 in unstimulated cells. Moreover, this was shown to occur in the absence of tyrosine phosphorylation (i.e., Stat $3^{\mathrm{Y} 705 \mathrm{~F}}$ accumulated in the nucleus in LMB-treated cells). These observations not only highlighted the existence of a previously uncharacterized basal nuclear export pathway, but also directly implied the existence of a basal nuclear import pathway. Of note, in Dictyostelium DdStat-c, a STAT homologue has been shown to translocate into the nucleus independently of tyrosine phosphorylation (33). Likewise, a very recent study, which exploited microinjected wheat germ agglutinin, suggested that low levels of Stat 1 may translocate into the nucleus in the absence of tyrosine phosphorylation (15). However, this pathway does not appear to be counterbalanced by a LMB-sensitive basal nuclear export pathway similar to the one we have identified for Stat3. Thus, it seems reasonable to speculate that differences in the balance between these two opposing pathways may account for the variation in nuclear Stat3 levels observed in different types of resting cells.

a

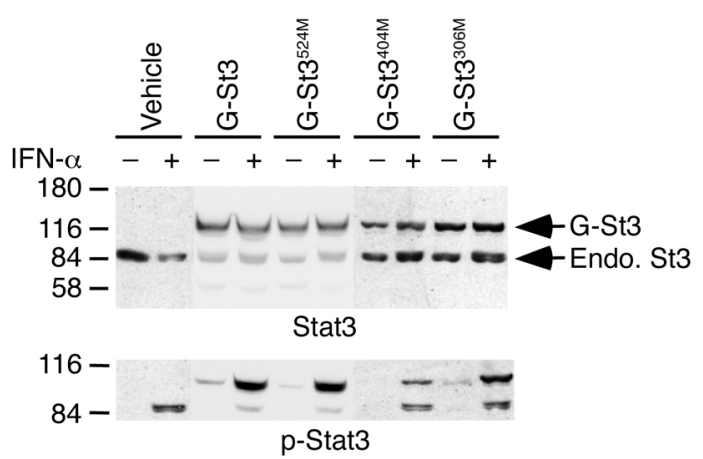

b

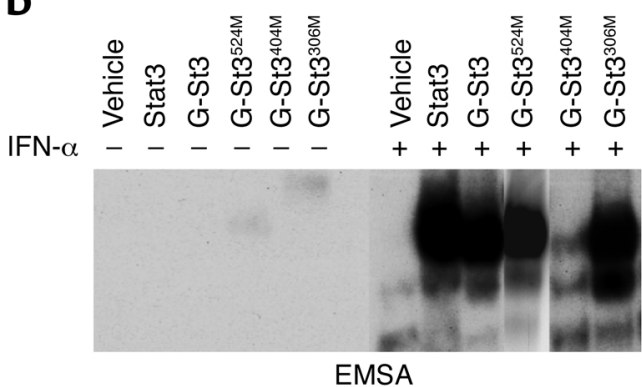



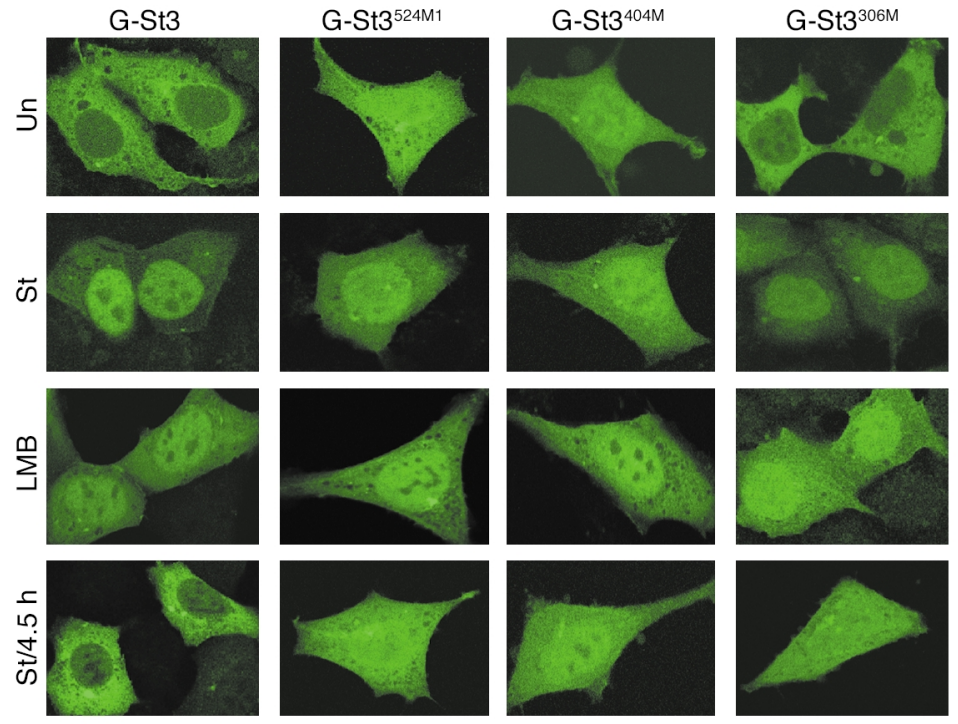

Figure 4

Subcellular distribution of GFP-Stat 3 mutants. Expression pattern of wild-type (G-St3) and mutant GFP-Stat3 (i.e., G-St3 ${ }^{524 M}$, G-St3 ${ }^{404 M}$, and G-St3 $306 \mathrm{M}$; see Table 1) $24 \mathrm{~h}$ after transfection in 293 cells after no treatment, stimulation with IFN- $\alpha(20 \mathrm{~min}, 1,000 \mathrm{U} / \mathrm{ml}), \operatorname{LMB}(7 \mathrm{~h}, 5-10 \mathrm{ng} / \mathrm{ml})$, and $4.5 \mathrm{~h}$ after acute treatment with IFN- $\alpha(20 \mathrm{~min}, 1,000 \mathrm{U} / \mathrm{ml})$. GFP fluorescence was evaluated in fixed cells with a $\times 63$ objective lens. These images are representative of more than 100 cells.

The basal export pathway outlined in these studies appears to serve two important functions. The first is to maintain cytoplasmic Stat3 at levels that are required for an adequate classical, i.e., ligand-dependent, signaling response. Additionally, the basal export pathway also appears poised to counterregulate the biological activity of basal nuclear Stat 3 . Although the nature of this basal activity has not been well defined, a number of studies have suggested that basal levels of Stat 1 and Stat 3 may serve to regulate caspase, c-myc, and FAS expression in unstimulated cells (34-36). More extensive gene array data comparing wild-type and Stat1-deficient cells have identified a number of genes whose expression appears to be regulated by Stat 1 in unstimulated cells, providing candidate targets of a basal response pathway (20). Corresponding, but technically more challenging, studies, exploring the pattern of genes expressed in Stat3-deficient cells may provide similarly important insight into the responses regulated by the basal Stat3 pathway.

Our studies directed at understanding how Stat3 nuclear export is regulated led to the identification of three NES elements, two of which have been found recently to regulate Stat 1 nuclear export (i.e., Stat $3^{306-318}$ and Stat $\left.3^{404-414}\right)(15,18,19)$, as well as one that has not been characterized previously (residues 524-535; see Table 1). Each of these three elements appears to be well conserved in other STAT family members (see Table 1), suggesting they are also likely to regulate the export of other STATs. Functional studies, with both a GFP-tagged reporter protein and mutation of these sites, indicate that these elements direct a bone fide Crm1-dependent nuclear export. Apparent differences in the relative potency of these elements in the two functional assays suggested that structural context might serve as an important regulator of NES activity. Consistent with this idea, the crystal structure of Stat 3 bound to DNA indicates that the NES element located in the DNA-binding domain (i.e., Stat $3^{404-414}$ ) is buried, rendering key hydrophobic residues solvent inaccessible (37). It has therefore been effectively argued that this element will only regulate export after the STAT complex is dissociated from DNA (18). Moreover, it has been suggested recently that this element may function as an NLS, as well (15-17), potentially confusing evaluation of this sequence in isolation, i.e., fused to a GFP-tagged reporter protein such as Rev1.4. Similarly, a second NES element (i.e., Stat $3^{524-535}$ ), which resides in the linker domain, is only partially exposed in the published Stat3 structure, again suggesting a conformation dependent activity. However, a third Stat $3^{306-318}$ NES, which is located in the coiled-coil domain, appears to be considerably more solvent accessible. Thus, it is possible that structural changes associated with Stat 3 activation may play an important role in regulating NES function.

The preceding studies support a model in which two mechanisms exist to regulate STAT transport into the nucleus. The first represents the well-characterized and rapid, ligand-dependent activation pathway (the classical import pathway). This is opposed by a rapid poststimulation export pathway. A second import pathway is active in unstimulated cells (i.e., basally) and functions independently of tyrosine phosphorylation. This pathway promotes the nuclear accumulation of low levels of Stat 1 (16) and Stat3 (our study) in resting cells. In the case of Stat3, a LMB-sensitive basal export pathway opposes this basal import pathway. This unique level of regulation may reflect the potent developmental and growth-promoting activities that have been attributed to $\operatorname{Stat} 3(6,38)$. Consistent with this complex regulation, mutation of two of the Stat 3 NES elements (i.e., Stat $3^{404-414}$ and Stat $3^{524-535}$ ) leads to a marked increase in the level of nuclear Stat 3 in resting cells, suggesting these elements regulate basal export. Structural studies suggest that access to these NES elements, and thus their activity, may be limited in the conformation associated with activated STATs, but this may not be the case with inactive Stat3 (J. Braunstein and C. Schindler, manuscript submitted for publication). In contrast, the Stat3 ${ }^{306-318}$ NES, which is more solvent accessible in the activated conformation, appears to play a more important role in postreceptor-stimulated export. 


\section{Acknowledgments}

The NIH (GM-54686) and the Burroughs Wellcome Fund supported these studies. We would like to thank T. Swayne and S. Swamy at Columbia University's NIH-supported Optical Microscopy Facility for technical assistance, B.R. Henderson for the Rev1.4 and Rev1.4NES DNA constructs, and $M$. Yoshida for his generous gift of leptomycin B.

1. Darnell, J.E., Jr. 1997. STATs and gene regulation. Science. 277:1630-1635.

2. Ihle, J.N. 2001. The Stat family in cytokine signaling. Curr. Opin. Cell Biol. 13:211-217.

3. Kisseleva, T., Bhattacharya, S., Braunstein, J., and Schindler, C.W. 2002 Signaling through the JAK/STAT pathway, recent advances and future challenges. Gene. 285:1-24.

4. Heinrich, P.C., Bernmann, I., Müller-Newen, G., Scharper, F., and Graeve, L. 1998. Interleukin-6-type cytokine signaling through the gp130/JAK/ STAT pathway. Biochem. J. 334:297-313.

5. Bromberg, J.F., et al. 1999. Stat3 as an oncogene. Cell. 98:295-303.

6. Bowman, T., Garcia, R., Turkson, J., and Jove, R. 2000. STATs in oncogenesis. Oncogene. 19:2474-2488.

7. Takeda, K. 1997. Targeted disruption of the mouse Stat3 gene leads to early embryonic lethality. Proc. Natl. Acad. Sci. USA. 94:3801-3804.

8. Schindler, C., Shuai, K., Prezioso, V., and Darnell, J.E. 1992. Interferondependent tyrosine phosphorylation of a latent cytoplasmic transcription factor. Science. 257:809-813.

9. Zhang, X., Blenis, J., Li, H.-C., Schindler, C., and Chen-Kiang, S. 1995 Requirement of serine phosphorylation for formation of STAT-promoter complexes. Science. 267:1990-1994.

10. Park, C., Lecomte, M.J., and Schindler, C. 1999. Murine Stat2 is uncharacteristically divergent. Nucleic Acids Res. 27:4191-4199.

11. Bild, A.H., Turkson, J., and Jove, R. 2002. Cytoplasmic transport of Stat3 by receptor-mediated endocytosis. EMBO J. 21:3255-3263.

12. Sekimoto, T., et al. 1997. Extracellular signal-dependent nuclear import of Stat 1 is mediated by nuclear pore-targeting complex formation with NPI-1, but not Rch1. EMBO J. 16:7076-7077.

13. Sekimoto, T., Nakajima, K., Tachibana, T., Hirano, T., and Yoneda, Y. 1996. Interferon- $\gamma$-dependent nuclear import of Stat 1 is mediated by the GTPase activity of Ran/TC4. J. Biol. Chem. 271:31017-31020.

14. Yu, C.L., Jin, Y.J., and Burakoff, S.J. 2000. Cytosolic tyrosine dephosphorylation of STAT5. Potential role of SHP-2 in STAT5 regulation. J. Biol. Chem. 275:599-604.

15. Meyer, T., Begitt, A., Lodige, I., van Rossum, M., and Vinkemeier, U. 2002. Constitutive and IFN-gamma-induced nuclear import of STAT1 proceed through independent pathways. EMBO J. 21:344-354.

16. McBride, K.M., Banninger, G., McDonald, C., and Reich, N.C. 2002. Regulated nuclear import of the STAT1 transcription factor by direct binding of importin-alpha. EMBOJ. 21:1754-1763.

17. Fagerlund, R., Melen, K., Kinnunen, L., and Julkunen, I. 2002. Arginine/lysine-rich nuclear localization signals mediate interactions between dimeric STATs and importin-alpha 5. J. Biol. Chem. 277:30072-30078

18. McBride, K.M., McDonald, C., and Reich, N.C. 2000. Nuclear export sig- nal located within theDNA-binding domain of the STAT1transcription factor. $E M B O J$. 19:6196-6206.

19. Begitt, A., Meyer, T., van Rossum, M., and Vinkemeier, U. 2000. Nucleocytoplasmic translocation of Stat 1 is regulated by a leucine-rich export signal in the coiled-coil domain. Proc. Natl. Acad. Sci. USA. 97:10418-10423.

20. Ramana, C.V., Gil, M.P., Schreiber, R.D., and Stark, G.R. 2002. Stat1dependent and -independent pathways in IFN-gamma-dependent signaling. Trends Immunol. 23:96-101.

21. Horvath, C.M., Wen, Z., and Darnell, J.E. 1995. A STAT protein domain that determines DNA sequence recognition suggests a novel DNA binding domain. Genes Devel. 9:984-994.

22. Henderson, B.R., and Eleftheriou, A. 2000. A comparison of the activity, sequence specificity, and CRM1-dependence of different nuclear export signals. Exp. Cell Res. 256:213-224.

23. Collum, R.G., Brutsaert, S., Lee, G., and Schindler, C. 2000. A Stat3-interacting protein (StIP1) regulates cytokine signal transduction. Proc. Natl. Acad. Sci. USA. 97:10120-10125.

24. Strehlow, I., and Schindler, C. 1998. Amino terminal signal transducer and activator of transcription (STAT) domains regulate nuclear translocation and STAT deactivation. J. Biol. Chem. 273:28049-28056.

25. Pine, R., Canova, A., and Schindler, C. 1994. Tyrosine phosphorylated p91 binds to a single element in the ISGF2/IRF-1 promoter to mediate induction by IFN- $\alpha$ and IFN- $\gamma$, and is likely to autoregulate the p 91 gene. EMBO J. 13:158-167.

26. Park, C., and Schindler, C. 1998. Protein-DNA interactions in interferon- $\gamma$ signaling. Methods: a companion to methods in enzymology. 15:175-188.

27. Kudo, N., et al. 1998. Leptomycin B inhibition of signal-mediated nuclear export by direct binding to CRM1. Exp. Cell Res. 242:540-547.

28. Zhong, Z., Wen, Z., and Darnell, J.E. 1994. Stat3: a STAT family member activated by tyrosine phosphorylation in response to epidermal growth factor and interleukin-6. Science. 264:95-98.

29. Fischer, U., Huber, J., Boelens, W.C., Mattaj, I.W., and Luhrmann, R. 1995. The HIV-1 Rev activation domain is a nuclear export signal that accesses an export pathway used by specific cellular RNAs. Cell. 82:475-483.

30. Mowen, K., and David, M. 2000. Regulation of STAT1 nuclear export by Jak1. Mol. Cell Biol. 20:7273-7281.

31. Haspel, R.L., and Darnell, J.E., Jr. 1999. A nuclear protein tyrosine phosphatase is required for the inactivation of Stat1. Proc. Natl. Acad. Sci. USA. 96:10188-10193.

32. ten Hoeve, J., et al. 2002. Identification of a nuclear Stat1 protein tyrosine phosphatase. Mol. Cell Biol. 22:5662-5668.

33. Fukuzawa, M., Araki, T., Adrian, I., and Williams, J.G. 2001. Tyrosine phosphorylation-independent nuclear translocation of a dictyostelium STAT in response to dif signaling. Mol. Cell. 7:779-788.

34. Ramana, C.V., et al. 2000. Regulation of c-myc expression by IFN-gamma through Stat1-dependent and -independent pathways. EMBO J. 19:263-272.

35. Kumar, A., Commane, M., Flickinger, T.W., Horvarth, C.M., and Stark, G.R. 1997. Defective TNF- $\alpha$ induced apoptosis in Stat 1 null cells due to low constitutive levels of caspases. Science. 278:1630-1632.

36. Ivanov, V.N., et al. 2001. Cooperation between Stat3 and c-Jun suppresses Fas transcription. Mol. Cell. 7:517-528.

37. Becker, S., Groner, B., and Müller, C.W. 1998. Three-dimensional structure of the Stat $3 \beta$ homodimer bound to DNA. Nature. 394:145-151.

38. Levy, D.E. 2002. Whence interferon? Variety in the production of interferon in response to viral infection. J. Exp. Med. 195:F15-F18. 